\title{
Intramural hematoma with gastric outlet obstruc- tion: a rare complication of endoscopic injection therapy for bleeding anastomotic ulcer
}
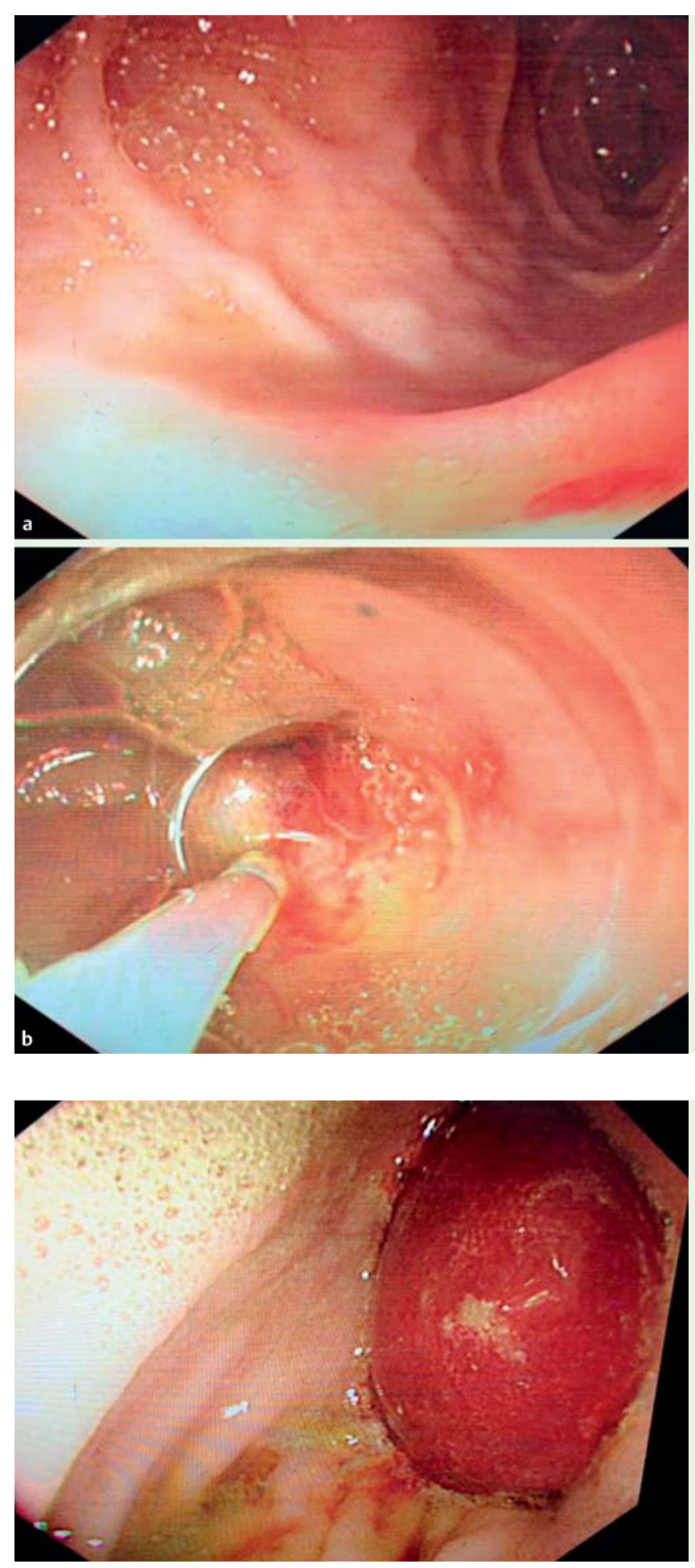

Fig. 1 Endoscopic views in a patient who had previously undergone partial gastrectomy showing: a blood oozing from an anastomotic ulcer; $\mathbf{b}$ the injection of $8 \mathrm{~mL}$ of diluted epinephrine to achieve hemostasis.

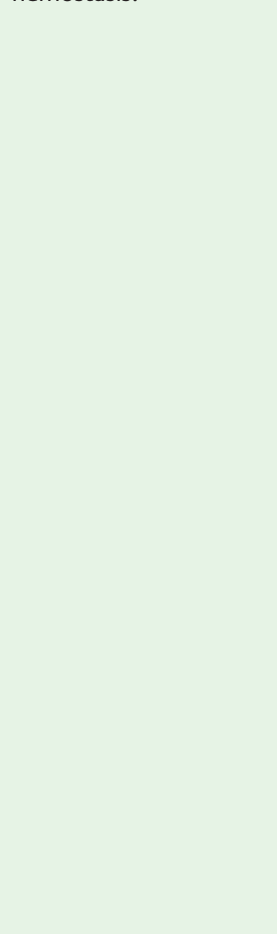

Fig. 2 Endoscopic appearance 3 days later showing a large intramural hematoma in the area of the injection site that was causing almost complete obstruction, such that the gastroscope was unable to pass through the stricture.

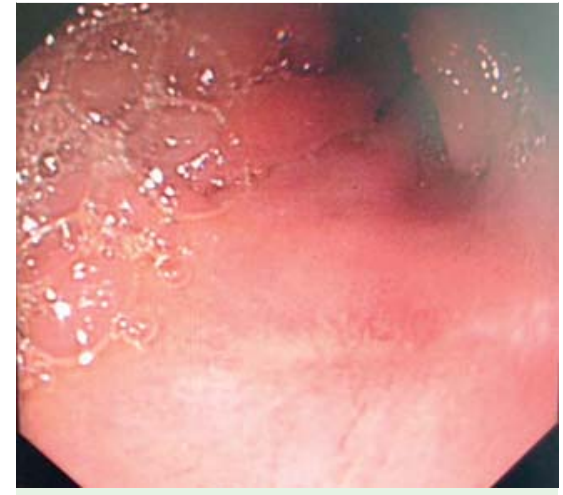

Fig. 3 Follow-up endoscopy 2 months later showing complete resolution of the hematoma.

A 66-year-old man was admitted to our department because of severe hematemesis and melena for 2 days. He had a history of gastric ulcer, which had been treated by a Billroth I partial gastrectomy 15 years previously. His hemoglobin was $3.4 \mathrm{~g} / \mathrm{dL}$ and he was transfused with 5 units of packed red blood cells. Laboratory tests revealed normal platelet count and coagulation profile. Endoscopy showed blood oozing from an anastomotic ulcer ( $\bullet$ Fig. 1 a). The bleeding was arrested by injecting approximately $8 \mathrm{~mL}$ of diluted epinephrine $(1: 10000)$ into and around the bleeding site ( $\mathbf{F i g . 1} \mathbf{b}$ ).

On the following day, the patient developed nausea and vomited the gastric contents, which consisted of greenish-yellow fluid. Follow-up endoscopy on day 3 revealed a large, intramural hematoma in the area of the injection site that was causing almost complete obstruction, such that the gastroscope was unable to pass through the stricture ( $\bullet$ Fig. 2). The patient was managed conservatively with fasting, nutritional support, and a proton pump inhibitor, and made a complete recovery. A follow-up endoscopy after 2 months revealed complete resolution of the hematoma ( $\bullet$ Fig.3).

Intramural hematoma of the gastrointestinal tract is an uncommon disorder. The causes of intramural hematoma include: coagulopathy [1], Ivor Lewis operation [2], endoscopic therapy [3], or spontaneous hematoma [4]. We believe that in this case the formation of the gastric in- 
tramural hematoma was due to the large volume of diluted epinephrine that was injected into the mucosa and submucosa. The arterioles in the submucosa or muscularis may have been damaged during deep and massive submucosal injection. Although this is the first case report of a gastric intramural hematoma with gastric outlet obstruction following endoscopic injection therapy for a bleeding anastomotic ulcer, clinicians should be alert to this potential complication to ensure its recognition and appropriate management. We advocate consideration of conservative management as the procedure of choice for gastric intramural hematoma.

Endoscopy_UCTN_Code_CPL_1AH_2AC

Competing interests: None

\section{Lei Shi, Fu Jian Liu, Qiu Hong Jia,} Hang Guang, Zhao Jiong Lu

Department of Gastroenterology, The Eighth Affiliated Hospital of Guangxi Medical University, Guangxi Zhuang Autonomous Region, China

\section{References}

1 Dhawan V, Mohamed A, Fedorak RN. Gastric intramural hematoma: a case report and literature review. Can J Gastroenterol 2009; 23: $19-22$

2 Cho S, Kim JW, Lee H et al. Intramural hematoma of gastric tube after Ivor Lewis operation. Ann Thorac Surg 2010; 89: 2016-2017

3 Yang CW, Yen $H H$. Large gastric intramural hematoma: unusual complication of endoscopic submucosal dissection. Endoscopy 2011; 43: 240

4 Secil M, Ucar G. Spontaneous duodenal hematoma. J Emerg Med 2004; 27: 291 293
Bibliography

Dol http://dx.doi.org/ 10.1055/s-0034-1365442

Endoscopy 2014; 46: E254-E255

(c) Georg Thieme Verlag KG

Stuttgart · New York

ISSN 0013-726X

\section{Corresponding author}

\section{Lei Shi, MD}

Department of Gastroenterology

The Eighth Affiliated Hospital of Guangxi Medical University

Guangxi Zhuang Autonomous Region

China

Fax: +86-775-4200028

ycymoment@hotmail.com 